

\title{
Game, set, and match: Do women and men perform differently in competitive situations?
}

\author{
Michael Jetter* Jay K. Walker ${ }^{\dagger}$
}

March 16, 2015

\begin{abstract}
This paper analyzes potential gender differences in competitive environments using a sample of over 100,000 professional tennis matches. Focusing on two phenomena of the labor and sports economics literature, we find robust evidence for (i) the hot-hand effect (an additional win in the most recent ten matches raises the likelihood of winning by 3.1 to 3.3 percent) and (ii) the clutch-player effect, as top players are excelling in Grand Slam tournaments, the most important events. Overall, we find virtually no gender differences for the hot-hand effect and only minor distinctions for the clutch-player effect.
\end{abstract}

JEL Classification: J24, L83, D84

Keywords: gender gap, competition, hot hand, clutch player, tennis

*until April 2015: Department of Economics, Universidad EAFIT, Carrera 49 \#7 Sur-50, Avenida Las Vegas, Medellín, Colombia; from July 2015: University of Western Australia, School of Business, Economics; Email: mjetter7@gmail.com Web: www.michaeljetter.com

${ }^{\dagger}$ Department of Economics and Finance, Bisgrove Hall, Room 254J, Niagara University, Lewiston, NY 14109, USA. Tel: +1 (716) 286-8311 Email: jwalker@niagara.edu Web: www.jaykwalker.com 


\section{Introduction}

Do men and women behave differently in competitive situations? Recent research suggests the average woman to be reluctant to compete (Gneezy et al., 2003; Niederle and Vesterlund, 2007; Niederle and Vesterlund, 2011) and generally differ in their attitude towards competitive situations (Byrnes et al., 1999; Eckel and Füllbrunn, 2015). Especially when trying to explain the persistent gender wage gap - which is not expected to be closed for another 70 years (Topping, 2015 ) - noncognitive skills and attitudes are proving to be important factors (Grove et al., 2011). ${ }^{1}$ However, most studies analyzing potential gender differences in competitive situations suffer from identification problems or lack information on other, potentially crucial characteristics. For instance, in most labor markets women work alongside men throughout their entire career and training, which makes it difficult to isolate performance measurements and disentangle behavior in the workplace from the influence of male colleagues.

Recently, labor markets in the sports world have become prominent laboratories for testing behavior in competitive situations. Reasons include the clear observability of outcomes (winning or losing) and a rich set of control and background information that is not normally available in business world environments (Kahn, 2000). Tennis as a single sport provides an ideal testing ground in this context, as professional tours are separated by gender, yet prize money has been very comparable in the past and has recently been equalized in the biggest events (also see Wozniak, 2012).

This paper uses all tennis matches on the main tours of every male and female tennis player who was ranked in September 2014 to analyze two major phenomena of the labor and sports economics literature: the hot-hand and clutch-player effects. The hot-hand effect states that recent, strong performances may affect current outcomes, whereas the clutch-player effect argues performance to increase when stakes are higher. Overall, our sample includes 107,566 tennis matches of 853 professional tennis players (424 males and 429 females). Taking advantage of a rich set of available control variables, our results contribute to three distinct branches of the economics literature.

First, we find strong evidence for the hot-hand effect. Even after controlling for rankings

\footnotetext{
${ }^{1}$ Other important aspects include historical origins and societal norms (Alesina et al., 2013; Burda et al., 2013), as well as socialization in early childhood (Andersen et al., 2013).
} 
(linear and squared), head-to-head characteristics of both players, and tournament-specific aspects, previously won matches are a positive and statistically meaningful predictor of winning the current match. In our most complete estimation, the marginal effect of having one additional winning encounter in the last ten matches raises the probability of winning by 3.1 to 3.3 percentage points. These results are in contrast to earlier findings by Gilovich et al. (1985) and further extend works by Abrevaya (2002), Livingston (2012), and Wozniak (2012). ${ }^{2}$

Second, the clutch-player effect emerges with force: top players perform their best in Grand Slam tournaments, arguably the most important dates of the tennis calendar. This confirms traditional theories of larger payoffs increasing incentives and therefore efforts (Lazear, 2000).

Third, we find virtually no gender differences for the hot-hand phenomenon and only very minor differences for the clutch-player effect. Both in terms of statistical importance and magnitudes, both men and women show evidence for the hot-hand effect in professional tennis matches. Regarding the clutch-player phenomenon, female top players actually appear more likely to compete well on big stages, although the effect is statistically meaningful for either gender. Only when looking at in-match performances do we find nuanced gender differences: top male players are more likely to win a tie-break when it matters most, whereas the respective result for the female sample remains statistically irrelevant.

These results are surprising given recent findings on gender differences in competitive environments (Niederle and Vesterlund, 2010; Niederle and Vesterlund, 2011; Niederle, 2014). A possible explanation could be the isolated, single-sex structure of tennis as a professional sport, as opposed to competing in mixed labor markets (see Gneezy et al., 2003). Thus, women may be as competitive as men when competing amongst themselves.

\section{Data}

Our sample data consists of all career matches of male and female tennis players who on September 21, 2014, were listed on the respective world rankings (ATP Tour for the men, WTA Tour for the women). Specifically, we focus on main ATP and WTA Tour matches, excluding tourna-

\footnotetext{
${ }^{2}$ Other studies analyze the hot-hand effect in the context of gambling, such as Croson and Sundali (2005) and Rabin and Vayanos (2010). Our approach is different as we are analyzing a skill-based sport, as opposed to gambling.
} 
ments on the minor Challengers and Futures Tours for lack of detailed data. On the ATP Tour this produces a total of 57,133 matches by 424 players, whereas the WTA sample includes 50,433 encounters and 429 players. ${ }^{3}$ In order to test for the hot-hand phenomenon and allow for the creation of variables capturing previous performance, we only use observations (i.e., matches) where the respective player has at least played ten previous matches on the respective Tour (ATP or WTA).

In addition to the large and comprehensive size of our sample a major advantage can be found in the rich set of control variables that the professional tennis organizations are offering for every match. In this context, Livingston (2012) points out that the hot-hand effect may have been masked by a lack of relevant control variables in previous studies. Our data includes rankings of both participating players, head-to-head histories, tournament specifics (tournament type, round, surface), and nationalities. Table 1 displays our summary statistics, comparing each variable between the male and female Tours. It is interesting to see that, besides the number of matches won and losing streaks, all variables show substantial differences across the male and female Tours. This further highlights the importance of incorporating meaningful control variables when estimating behavior in competitive environments, such as the hot-hand or the clutch-player effects.

Notice that 53 to 54 percent of all matches were won by the reference player, indicating that a number of players who lost matches are not playing professional tennis tournaments anymore. In general, if both participating players of a match are ranked at the time of data collection the match enters our sample twice: once from the respective player's perspective and once from the opponent's perspective (similar to the data structure in Duggan and Levitt, 2002). In terms of our main variables of interest, women have won more of their previous ten matches and enjoy longer winning streaks on average. Further, on the WTA Tour players are more likely to have faced each other before (16 percent of matches are first-time encounters), suggesting a smaller turnaround of players over time. Further, the average female player is substantially younger

\footnotetext{
${ }^{3}$ The earliest match in our male sample took place in March 1997, whereas the first match of the female sample dates back to May 1989. The reason for such an early match in the female sample can be traced back to Kimiko Date-Krumm (from Japan, born 1970), who returned to professional tennis at the age of 37 in April 2008 and is still playing today at the age of 43. The last match in both samples comes from the week before our data collection (September 21, 2014). All data are derived from the ATP and WTA websites (http://www.atpworldtour.com/ and http://www.wtatennis.com/).
} 
Table 1: Summary statistics

\begin{tabular}{|c|c|c|c|}
\hline Variable & $\begin{array}{l}\text { Mean ATP } \\
\text { (Std. Dev.) }\end{array}$ & $\begin{array}{l}\text { Mean WTA } \\
\text { (Std. Dev.) }\end{array}$ & $\begin{array}{c}\text { T-test } \mathrm{ATP}=\mathrm{WTA} \\
(\mathrm{p} \text {-value })\end{array}$ \\
\hline Winning match & $\begin{array}{c}0.53 \\
(0.50)\end{array}$ & $\begin{array}{c}0.54 \\
(0.50)\end{array}$ & 0.23 \\
\hline \# of wins in last 10 matches & $\begin{array}{c}5.35 \\
(1.78)\end{array}$ & $\begin{array}{c}5.43 \\
(1.79)\end{array}$ & $0.00^{* * *}$ \\
\hline Ranking & $\begin{array}{l}94.03 \\
(99.54)\end{array}$ & $\begin{array}{c}95.67 \\
(87.80)\end{array}$ & $0.00^{* * *}$ \\
\hline Opponent's ranking & $\begin{array}{c}126.04 \\
(184.92)\end{array}$ & $\begin{array}{c}115.42 \\
(132.45)\end{array}$ & $0.00^{* * *}$ \\
\hline Never faced opponent before & $\begin{array}{c}0.18 \\
(0.38)\end{array}$ & $\begin{array}{c}0.16 \\
(0.36)\end{array}$ & $0.00^{* * *}$ \\
\hline Never beaten opponent & $\begin{array}{c}0.46 \\
(0.50)\end{array}$ & $\begin{array}{c}0.56 \\
(0.50)\end{array}$ & $0.00^{* * *}$ \\
\hline From same country & $\begin{array}{c}0.07 \\
(0.26)\end{array}$ & $\begin{array}{c}0.06 \\
(0.23)\end{array}$ & $0.00^{* * *}$ \\
\hline Grand Slam & $\begin{array}{c}0.22 \\
(0.42)\end{array}$ & $\begin{array}{c}0.21 \\
(0.41)\end{array}$ & $0.00^{* * *}$ \\
\hline \# of wins in last 5 matches & $\begin{array}{c}2.68 \\
(1.13)\end{array}$ & $\begin{array}{c}2.71 \\
(1.14)\end{array}$ & $0.00^{* * *}$ \\
\hline Winning streak (max. 10 matches) & $\begin{array}{c}1.15 \\
(1.68)\end{array}$ & $\begin{array}{c}1.17 \\
(1.65)\end{array}$ & $0.07^{*}$ \\
\hline Losing streak (max. 10 matches) & $\begin{array}{c}0.87 \\
(1.35)\end{array}$ & $\begin{array}{c}0.86 \\
(1.35)\end{array}$ & 0.18 \\
\hline Age in years & $\begin{array}{l}25.5 \\
(3.45)\end{array}$ & $\begin{array}{l}21.98 \\
(4.36)\end{array}$ & $0.00^{* * *}$ \\
\hline Experience on Tour in years & $\begin{array}{c}6.02 \\
(3.15)\end{array}$ & $\begin{array}{c}7.05 \\
(3.81)\end{array}$ & $0.00^{* * *}$ \\
\hline Observations & 57,133 & 50,433 & \\
\hline
\end{tabular}


than the average male player, although the reverse is true when considering experience (time since first professional match in years). This highlights the fact that girls enter the professional tennis arena much earlier than boys (Guillaume et al., 2011).

\section{Methodology}

Given the data described in Table 1, we test professional tennis matches for two main phenomena that have drawn attention in the associated labor and sports literatures: the hot-hand and the clutch-player effects. The former effect states that when an athlete is "hot" (cold), meaning that she has performed well (badly) in immediately preceding competitions, her likelihood of performing well increases (decreases). Some research has found affirmative (Abrevaya, 2002, for

bowling; Livingston, 2012, for golf; Wozniak, 2012, for tennis) and others contradictive evidence for the hot-hand effect (Gilovich et al., 1985, for basketball; Bar-Eli et al., 2006, in general). The latter argument focuses on the size of the payoff at stake, putting workers under increased pressure (Dohmen, 2008; Ariely et al., 2009). Previous literature has suggested and presented evidence for two contradicting hypotheses in this context. For once, very large payoffs can lead to mistakes (Ariely et al., 2009; Apesteguia and Palacios-Huerta, 2010), but may also increase effort levels (Lazear, 2000).

To test both phenomena, we employ conventional logit regressions, estimating the likelihood of a player winning a tennis match. For the hot-hand effect, we construct several versions of the main independent variable. First, we incorporate a variable measuring the number of wins in the last ten matches of the respective player. If the derived coefficient then takes on a positive and statistically meaningful value, this would provide evidence for the existence of the hot-hand effect. Notice that in every tennis tournament only one player eventually remains unbeaten, whereas all other players (31 in a draw of $32 ; 63$ in a draw of 64 ) suffer a loss. Thus, using the number of wins in the past ten matches provides a more lenient definition of the hot-hand phenomenon. Nevertheless, section 4.2 provides results from incorporating pure, uninterrupted winning and losing streaks. In addition, we control for other factors that are likely to affect

the probability of a victorious outcome, namely the current ranking (linear and squared), the opponent's ranking, head-to-head information (whether both players played against each other 
before, whether the opponent was beaten at least once before, whether both players originate from the same country), and match specifics (fixed effects for tournament category, round, and surface). ${ }^{4}$

Our strategy for testing the clutch-player effect then builds on this framework by incorporating an interaction term between a player's ranking and the importance of the respective match. Clearly, the four Grand Slam tournaments stand out on both the ATP and the WTA Tours: the Australian Open, French Open, Wimbledon, and the US Open. Both in terms of prize money and prestige, these events mark the highlights of the tennis calendar. Table 2 visualizes the extraordinary importance of the four Grand Slam tournaments, as indicated by prize money. In addition, we then analyze crucial situations within a match, namely whether top players are more likely to prevail in decisive sets and tie-breaks when playing at Grand Slam events.

Table 2: Total prize money for the ten biggest tournaments in 2014, all in US\$ (exchange rates taken on March 8, 2015).

\begin{tabular}{|c|c|c|c|}
\hline \multicolumn{2}{|c|}{ Men's Tour } & \multicolumn{2}{|l|}{ Women's Tour } \\
\hline Tournament & Prize money & Tournament & Prize money \\
\hline US Open & $19,125,880$ & US Open & $19,125,880$ \\
\hline Wimbledon & $18,800,000$ & Wimbledon & $18,800,000$ \\
\hline French Open & $13,551,487$ & French Open & $13,551,487$ \\
\hline Australian Open & $12,715,725$ & Australian Open & $12,715,725$ \\
\hline London (Masters) & $6,500,000$ & Singapore (WTA Finals) & $6,500,000$ \\
\hline Indian Wells & $5,240,015$ & Indian Wells & $5,946,740$ \\
\hline Miami & $4,720,380$ & Beijing & $5,427,105$ \\
\hline Shanghai & $4,195,895$ & Miami & $5,427,105$ \\
\hline Madrid & $3,977,233$ & Madrid & $4,942,700$ \\
\hline Cincinnati & $3,356,715$ & Wuhan & $2,440,070$ \\
\hline Toronto & $3,146,920$ & Qatar, Montreal, Cincinnati & $2,369,000$ \\
\hline
\end{tabular}

In terms of identifying star players, we take several approaches. First, we incorporate a binary variable for whether a player is ranked in the top four of the rankings. Naturally, the top ranked four players are always seeded in the tournament bracket in a way that does not allow

\footnotetext{
${ }^{4}$ We include binary indicators for tournament types of ATP, WTA, and Grand Slam tournaments. Round fixed effects include final, semifinal, quarterfinal, round of 16 , round of 32, round of 64 , round of 128 , qualification rounds, and group stages (Masters). Dummies for surface types are carpet, clay, hard, and grass courts.
} 
them to meet before the semifinal. On the men's Tour this list includes (almost exclusively over the past eight years) Roger Federer, Novak Djokovic, Rafael Nadal, and Andy Murray. ${ }^{5}$ In fact, in the ten years from 2004 to 2013 these four players have won 37 of all 40 Grand Slam titles. On the women's side, the list is a bit longer, incorporating overall 16 players. ${ }^{6}$

In order to assess whether top players perform when it matters most, we create an interaction term between players who are ranked in the top four and Grand Slam tournaments. If a clutch-player effect were to exist in professional tennis, we would expect star players to perform exceptionally well in the most important events, Grand Slam tournaments. We then also apply a more continuous measurement of identifying top players by using pure rankings in an interaction term with Grand Slam matches. Here again, we display several robustness check (e.g., using top ten or only well-established players on the tour with at least 50 matches).

\section{Empirical Findings for the Hot-Hand Phenomenon}

Starting with the evaluation of the hot-hand phenomenon, Tables 3 to 7 display our main results from logit regressions. We first present our baseline findings, before moving to several extensions and robustness checks. Finally, Section 4.3 considers potential heterogeneities along the lines of age and experience. Throughout all tables, we usually display the results from the ATP sample in the first four columns, followed by the WTA sample in columns (5) to (8). All our results are virtually identical when using a probit model.

\subsection{Main Results}

Table 3 shows regressions coefficients from estimating the probability to win a match, trying to isolate the effect of recent performances. Specifically, we start with a univariate regression using the number of wins out of the last ten matches as a sole predictor. Notice that for both men and women the coefficient is negative, statistically powerful, and remarkably similar $(0.033$

\footnotetext{
${ }^{5}$ The only other players to break into this elusive group throughout our entire sample period (albeit for relatively short periods of time) are Nikolay Davydenko, David Ferrer, Tommy Haas, Lleyton Hewitt, Juan Martin Del Potro, and Stanislas Wawrinka.

${ }^{6}$ These players are Victoria Azarenka, Eugenie Bouchard, Simona Halep, Ana Ivanovic, Jelena Jankovic, Svetlana Kuznetsova, Petra Kvitova, Na Li, Nadia Petrova, Agniezska Radwanska, Francesca Schiavone, Maria Sharapova, Serena and Venus Williams, Caroline Wozniacki, and Vera Zvonareva.
} 
to 0.034$)$. Taken literally, every win in the last ten matches is suggested to raise the chances of winning the current match by 3.3 to 3.4 percentage points. In the extreme case of having won all previous ten matches, this effect can become sizeable and increase one's likelihood of prevailing victoriously by 33 to 34 percentage points.

However, this univariate regression does not acknowledge the importance of other factors that can be crucial in predicting a winner. Most notably, current rankings of both players are probably the most obvious indicators and columns (2) and (6) add these factors to the model. Notice that we divide all rankings by 100 to facilitate readability of the derived coefficients. As expected, both a better ranking (a lower number) and a worse ranking of the opponent (a higher number) raise the chances of winning. Notice also that rankings seem to matter slightly more on the female Tour, as magnitudes are usually about 30 percentage points higher in columns (6) through (8). Throughout all our estimations, this finding remains remarkably consistent, both in terms of statistical relevance and magnitude. Regarding our variable of interest, the coefficient on the number of past wins drops to 0.28 to 0.29 , but comfortably retains its statistical importance. In additional estimations (available upon request) we also incorporated the average ranking of past opponents, but the hot-hand effect persists and does not seem to be driven by whom one has beaten previously.

The final two columns of the male and female sample then include head-to-head characteristics, a dummy for Grand Slam tournaments, but also fixed effects for the specific playing surfaces (carpet, clay, hard court, and grass) and rounds (final, semifinal, etc.). It is interesting to see that not having faced an opponent before lowers the odds of winning and so does the fact of playing at a Grand Slam tournament. The reason for the latter finding can likely be found in the strong field of participants at Grand Slams, where the cutoff for participation is usually around \#104 in a field of 128 players. $^{7}$ Thus, very few low ranked players participate, making it more difficult to advance.

In general, the estimated coefficients conform to our initial intuition and we find a robust relationship between the number of wins in the recent past and the odds of winning the current encounter. Not only is the effect strong in statistical terms, but also remains sizeable when adding the mentioned list of control variables. In fact, the coefficient only decreases marginally

\footnotetext{
${ }^{7}$ The remaining spots are allocated through a qualifying tournament and "Wild Cards."
} 


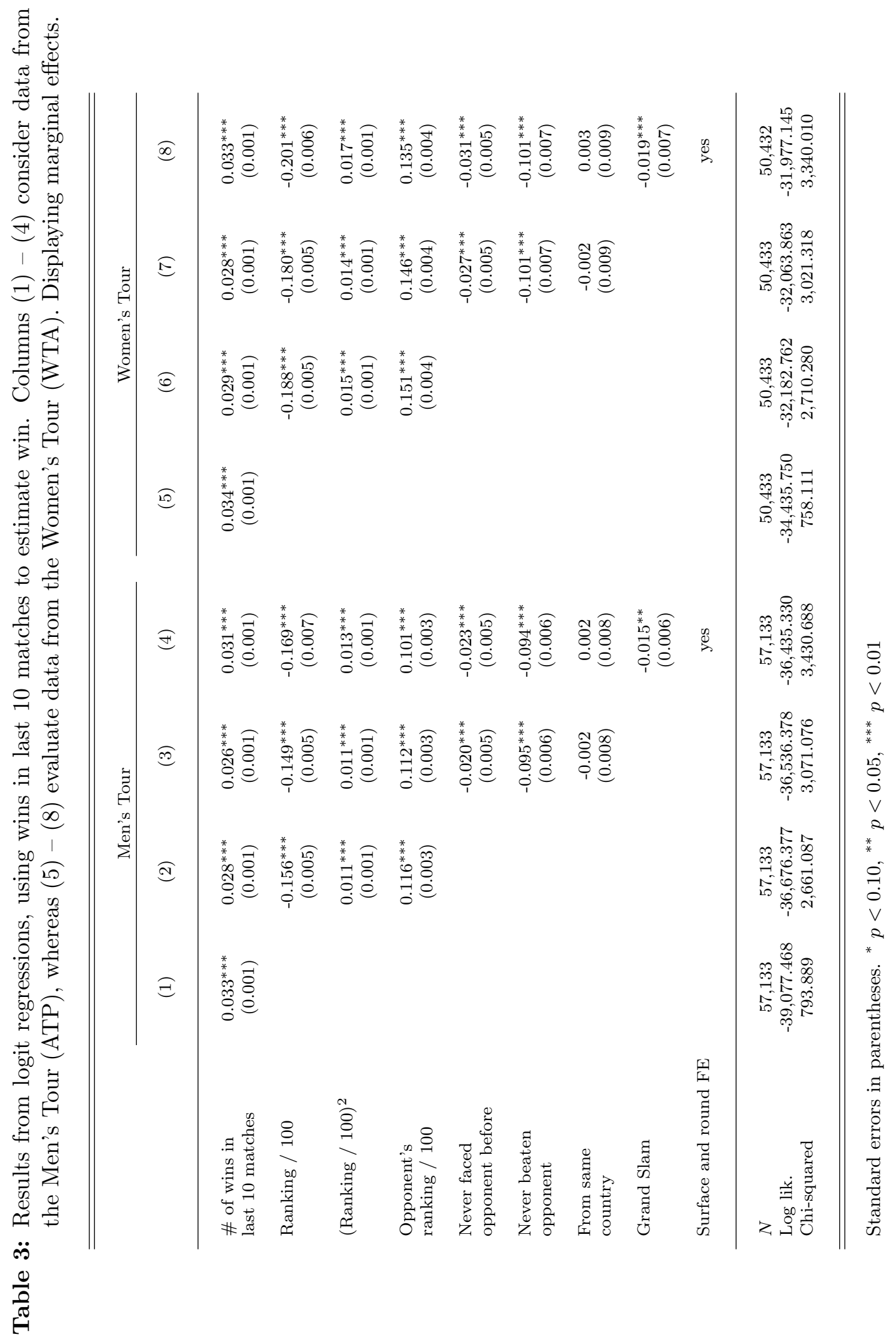


from 0.033 to 0.031 for the males and from 0.034 to 0.033 for the females. Thus, every recent victory bolsters the odds of winning the current match by 3.1 to 3.3 percentage points. Figure 1 visualizes these findings in a simple graph.
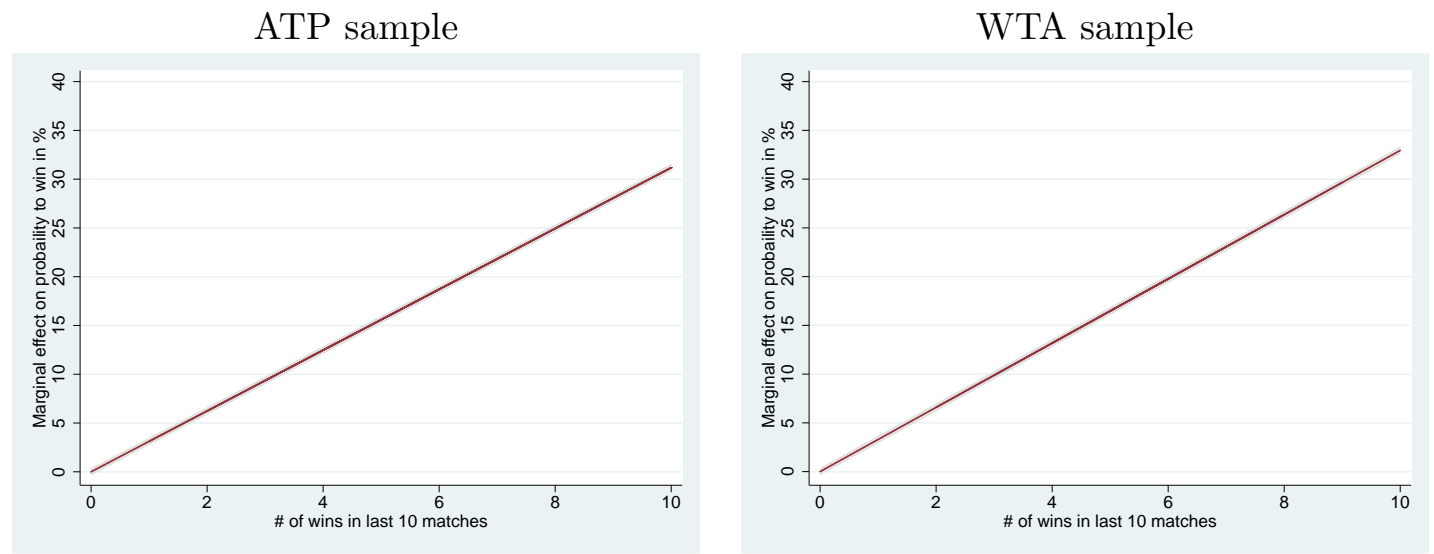

Figure 1: Marginal effect of wins in last 10 matches on chances of winning a match (all other covariates taken at their mean).

A remarkable conclusion relates to the fact that we find virtually no gender differences for the hot-hand effect in tennis, supplementing Livingston (2012) who studies professional golf tours. This finding is even more surprising given the substantial differences between the ATP and WTA matches in basic summary statistics (see Table 1). The following sections will now discuss results from further testing this hypothesis.

\subsection{Robustness Checks and Extensions}

Table 4 displays several alternative specifications of our baseline findings (final columns of Table 3), once again dedicating columns (1) through (4) to the male sample and (5) through (8) to the WTA data. Columns (1) and (5) now use more recent performance as a measurement for having a hot hand by just considering the last five Tour matches. Notice that the previous results are confirmed and magnitudes even increase by about one third towards 0.04 (men) and 0.045 (women). Thus, the last ten matches matter, but the most recent 5 encounters matter even more. Once again, logit regressions from using ATP and WTA data return the same level of statistical significance and remarkably similar magnitudes.

The remaining regressions displayed return to using performance of the previous ten matches 


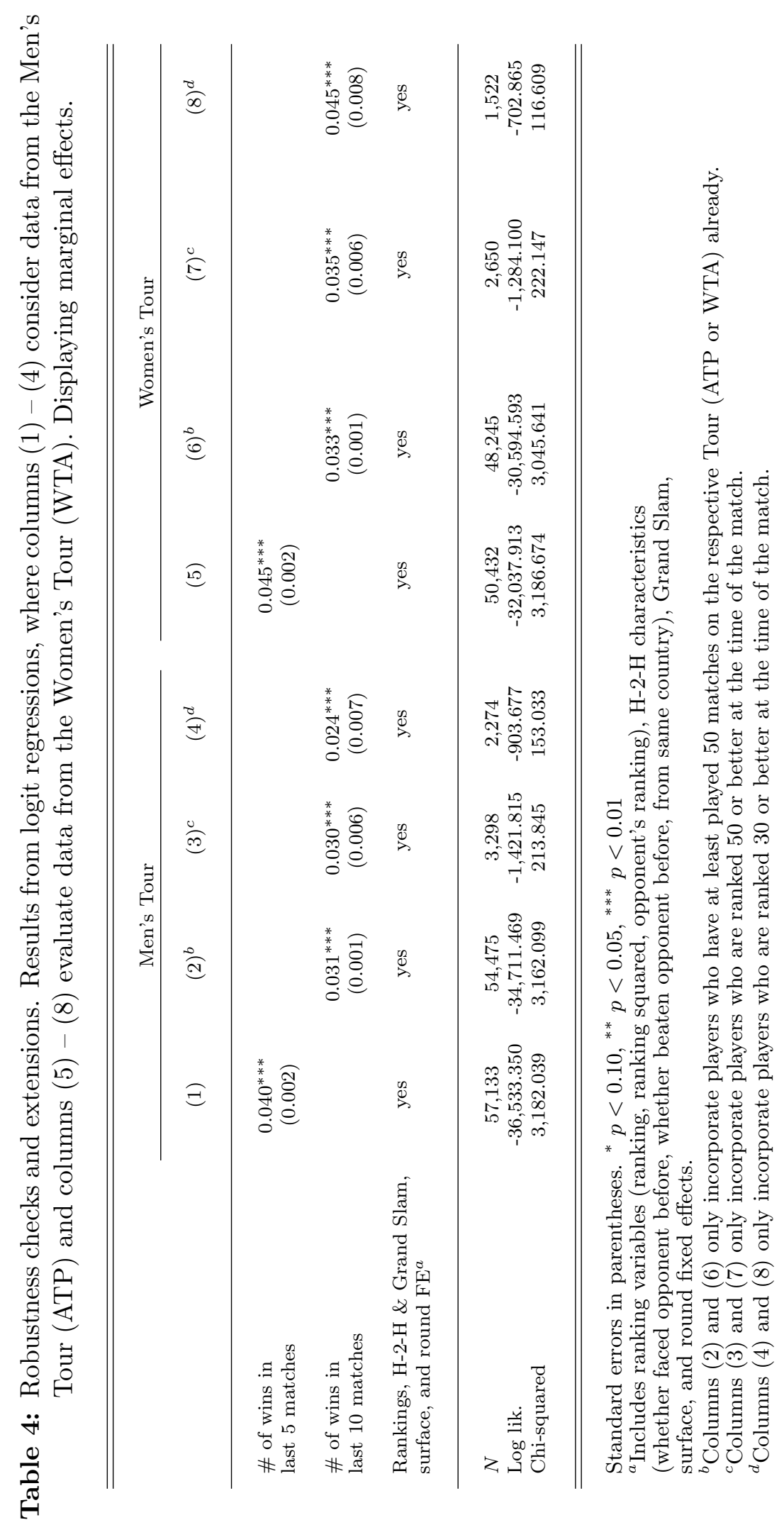


as an indicator for whether a player is currently hot. Specifically, we consider three distinct subsamples that are intended to address potential heterogeneities within our original data. For instance, if players have recently entered the professional tour, then current rankings could be misleading. ${ }^{8}$ Thus, we repeat our baseline estimation, but only use observations where the respective player has at least competed in 50 Tour matches. Further, columns (3) and (7) display results from only using established players ranked 50 or better, whereas columns (4) and (8) further derive subsamples of players ranked 30 or better. Both of these subsets serve the purpose of making our sample more homogeneous, ensuring that outliers in terms of ranking are not driving our results. However, looking at the derived results throughout Table 4 confirms our initial finding of a sizeable and persistent hot-hand effect, both for male and female tennis professionals.

Beyond using the number of wins in the past ten encounters, Table 5 moves to a more restrictive definition of the hot-hand (cold-hand) phenomenon: a pure winning (losing) streak of the number of consecutively won (lost) matches. The first two columns, respectively, consider a winning streak of maximum ten matches, whereas the remaining columns incorporate losing streaks. ${ }^{9}$ Starting with winning streaks, we once again find strong evidence for the hot-hand hypothesis, especially when adding the usual control variables. As before, the derived coefficient from using the male and female data are virtually identical, suggesting that every additional win in a streak increases the chances to win again by 1.7 percentage points.

Moving to losing streaks, a measurement for the cold-hand phenomenon, we also find strong evidence. Interestingly, the estimates remain close in magnitude to the ones derived for winning streaks, indicating that winning streaks are rewarded in a similar way as losing streaks are punished. In terms of potential gender differences, losing streaks seem to be punished more on the WTA Tour, where each loss decreases the chances of winning by 2.0 percentage points slightly more than the 1.6 percentage points on the ATP Tour.

Overall, however, our robustness checks and extensions confirm our initial finding of a remarkably similar hot-hand effect for males and females in labor markets that are by design

\footnotetext{
${ }^{8}$ As a famous example, John McEnroe, when emerging on the Tour, was asked how he feels about beating all these better ranked opponents. His response was that he is the best player in the world, but his ranking hasn't caught up with him yet.

${ }^{9}$ Given our basic sample restriction of only using observations where the respective player has at least played ten Tour matches previously, we limit streaks to ten.
} 


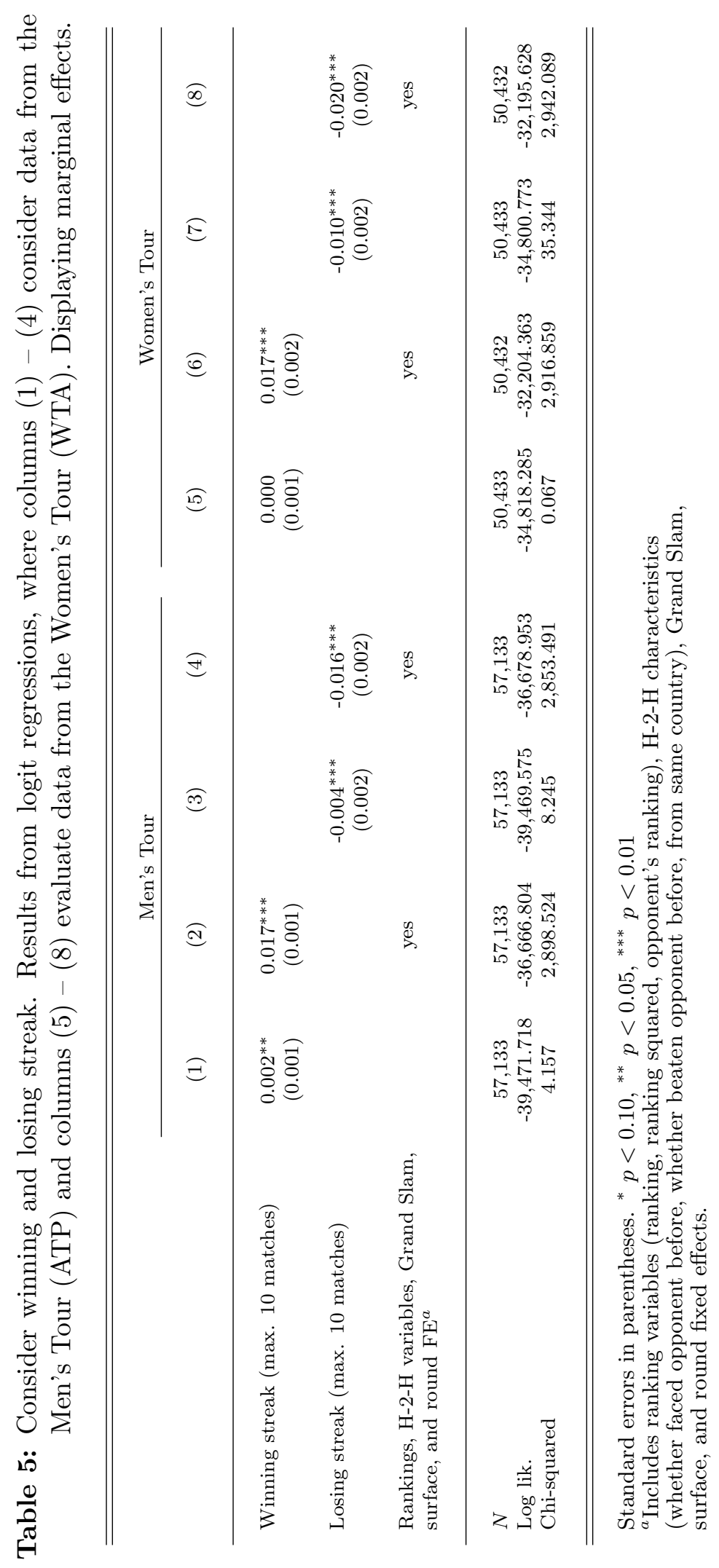


gender-separated, yet exhibit almost identical payoff schemes. The next section will now consider further extensions, addressing a potential heterogeneity along the lines of age and experience.

\subsection{Age and Experience}

Livingston (2012) uses data from professional golf to show that only analyzing hot-hand effects at the conditional mean can be misleading. Specifically, he finds that the hot-hand effect emerges particularly for inexperienced golfers on the Nationwide Tour. Although our results up to now strongly support the existence of a general hot-hand effect, it can be interesting to consider potential nonlinearities. Given our data, we readily create two variables capturing experience. Specifically, we use a player's age at the time of the match, but also her experience, measured as the time since her first appearance on Tour. For either variable, we then create an interaction term between the number of matches won recently and the respective experience variable.

Table 6 displays the respective results, dedicating columns (1) and (2) to the male data, before moving to the female sample in columns (3) and (4). Incorporating age and its interaction term with recent wins produces no statistically relevant coefficients. However, when using experience rather than age we do find an interesting particularity. Most notably, experience in general diminishes the chances of success on the ATP Tour, yet has no statistically relevant

impact on the WTA Tour. Related to the hot-hand hypothesis, experience further increases its importance. This is in stark contrast to Livingston (2012)'s findings that suggest the opposite. Although the effect is relatively minor in size - ten years of experience and one additional recent victory raise the odds of winning by one percentage point - the statistical importance of the effect emerges with force. Notice that we do not find this anomaly for the female data.

Further, Table 7 re-estimates these potential nonlinearities for age and experience using pure winning and losing streaks. When choosing streaks as a measurement for the hot-hand hypothesis results are more nuanced. Now we confirm Livingston (2012)'s results, at least for the male data in column (1): older players are less prone to the hot-hand effect. As for women, we find the opposite conclusion, although this result remains weak, both in terms of conventional levels of statistical significance and magnitude in column (5). Overall, the interaction terms in Table 7 remain mostly insignificant and negligible in terms of size. Thus, the results from incorporating age and experience into the hot-hand estimation are mixed and do not paint a 
Table 6: Considering differences by age and experience for hot-hand effect. Results from logit regressions, where columns (1) - (4) consider data from the Men's Tour (ATP) and columns (5) - (8) evaluate data from the Women's Tour (WTA). Displaying marginal effects.

\begin{tabular}{|c|c|c|c|c|}
\hline & \multicolumn{2}{|c|}{ Men's Tour } & \multicolumn{2}{|c|}{ Women's Tour } \\
\hline & $(1)$ & $(2)$ & $(3)$ & $(4)$ \\
\hline \# of wins in last 10 matches & $\begin{array}{c}0.041^{* * *} \\
(0.009)\end{array}$ & $\begin{array}{c}0.023^{* * *} \\
(0.003)\end{array}$ & $\begin{array}{c}0.027^{* * *} \\
(0.006)\end{array}$ & $\begin{array}{c}0.029^{* * *} \\
(0.003)\end{array}$ \\
\hline Age & $\begin{array}{l}-0.002 \\
(0.002)\end{array}$ & & $\begin{array}{c}-0.003^{* *} \\
(0.002)\end{array}$ & \\
\hline Age $\times \#$ of wins in last 10 matches & $\begin{array}{l}-0.000 \\
(0.000)\end{array}$ & & $\begin{array}{c}0.000 \\
(0.000)\end{array}$ & \\
\hline Experience & & $\begin{array}{c}-0.005^{* *} \\
(0.002)\end{array}$ & & $\begin{array}{l}-0.003 \\
(0.002)\end{array}$ \\
\hline Experience $\times \#$ of wins in last 10 matches & & $\begin{array}{c}0.001^{* * *} \\
(0.000)\end{array}$ & & $\begin{array}{c}0.000 \\
(0.000)\end{array}$ \\
\hline $\begin{array}{l}\text { Rankings, } \mathrm{H}-2-\mathrm{H} \text { variables, Grand Slam, } \\
\text { surface, and round } \mathrm{FE}^{a}\end{array}$ & yes & yes & yes & yes \\
\hline$N$ & 57,133 & 57,133 & 50,432 & 50,432 \\
\hline Log lik. & $-36,410.262$ & $-36,424.084$ & $-31,971.013$ & $-31,975.925$ \\
\hline & $3,461.252$ & & $3,348.277$ & $3,341.877$ \\
\hline
\end{tabular}

Standard errors in parentheses. ${ }^{*} p<0.10,{ }^{* *} p<0.05,{ }^{* * *} p<0.01$

${ }^{a}$ Includes ranking variables (ranking, ranking squared, opponent's ranking), H-2-H characteristics (whether faced opponent before, whether beaten opponent before, from same country), Grand Slam, surface, and round fixed effects. 
clear picture, especially when compared to our baseline findings and the respective extensions. With these results in mind, we now move to regressions results addressing the clutch-player effect.

\section{Empirical Findings for the Clutch-Player Phenomenon}

Performance in high-pressure situations has long been analyzed not only in the labor literature, but also in specific sports environments. As pointed out by Dohmen (2008) and Ariely et al. (2009), large rewards can not only provide motivation and increase effort levels (Lazear, 2000), but can also paralyze. Applied to tennis, some tournaments are naturally more important than others. The tennis season reaches its highlights with the four Grand Slam tournaments and we wish to test whether top players actually do perform well there, i.e., are clutch players, or if they can be overwhelmed by the pressure - something that is oftentimes referred to as choking in the sports world.

\subsection{Performance at Grand Slam Events}

Table 8 estimates the probability of winning a particular match, where we again distinguish between the male sample in columns (1) through (4) and the female sample in (5) through (8). To estimate whether top-ranked players perform exceptionally in Grand Slam events, we first use an interaction term between a dummy for players ranked in the top four and Grand Slams, while also controlling for both aspects individually. Both in the basic regressions and when adding our initial set of covariates in columns (2) and (6) the interaction term returns a positive and statistically powerful coefficient. Taken literally, a top four ATP player is ten percentage points more likely to win a match at a Grand Slam tournament, as opposed to any other event throughout the year. The effect emerges as well for females, yet with a smaller magnitude of 7.8 percentage points.

However, using a binary indicator for top four players may still be too general - an arbitrary cutoff, albeit based on empirical observations (especially on the ATP Tour the top four players have dominated the recent years almost exclusively). Thus, the remaining columns choose the most continuous and objective measurement of player quality by incorporating an interaction 


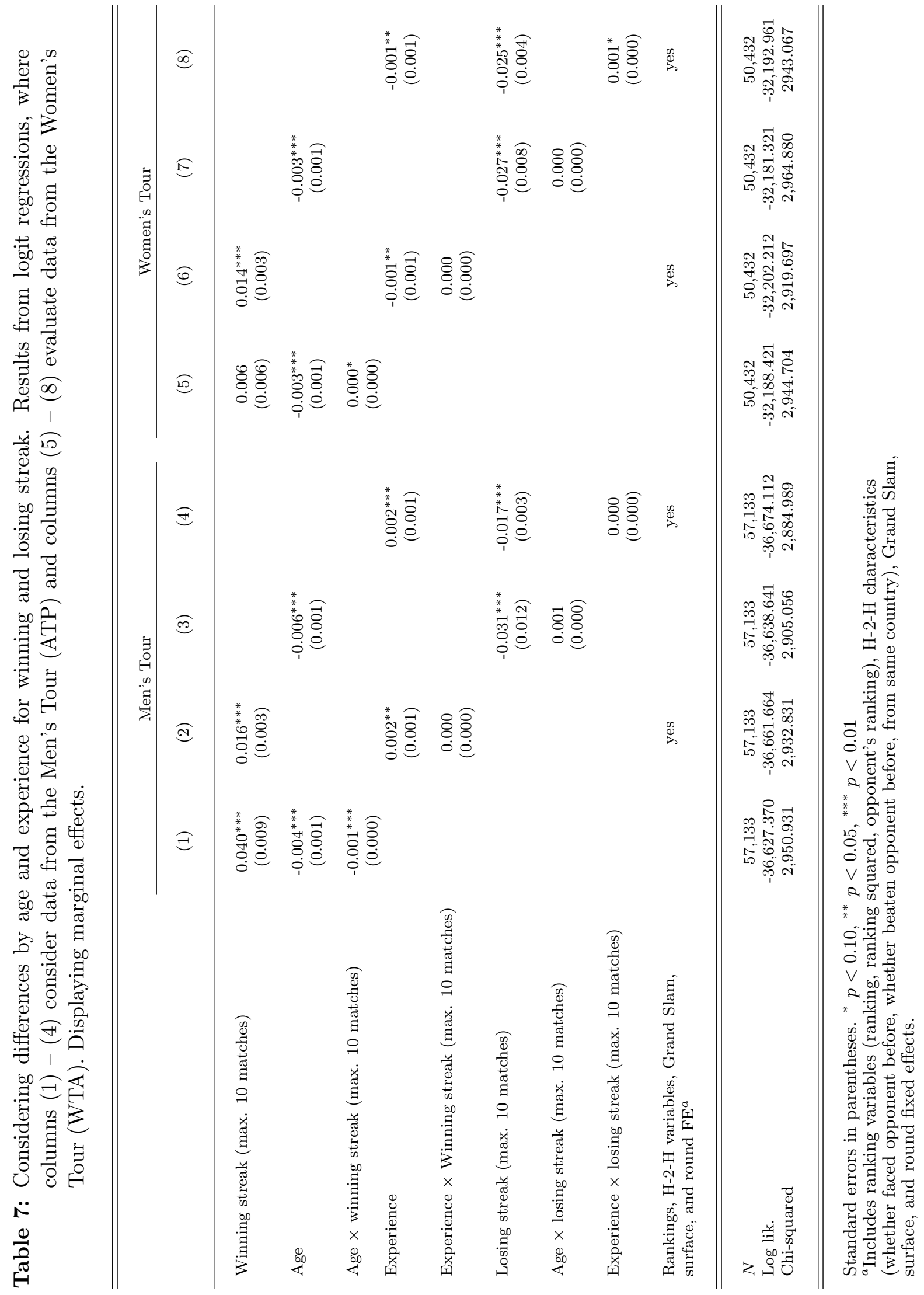




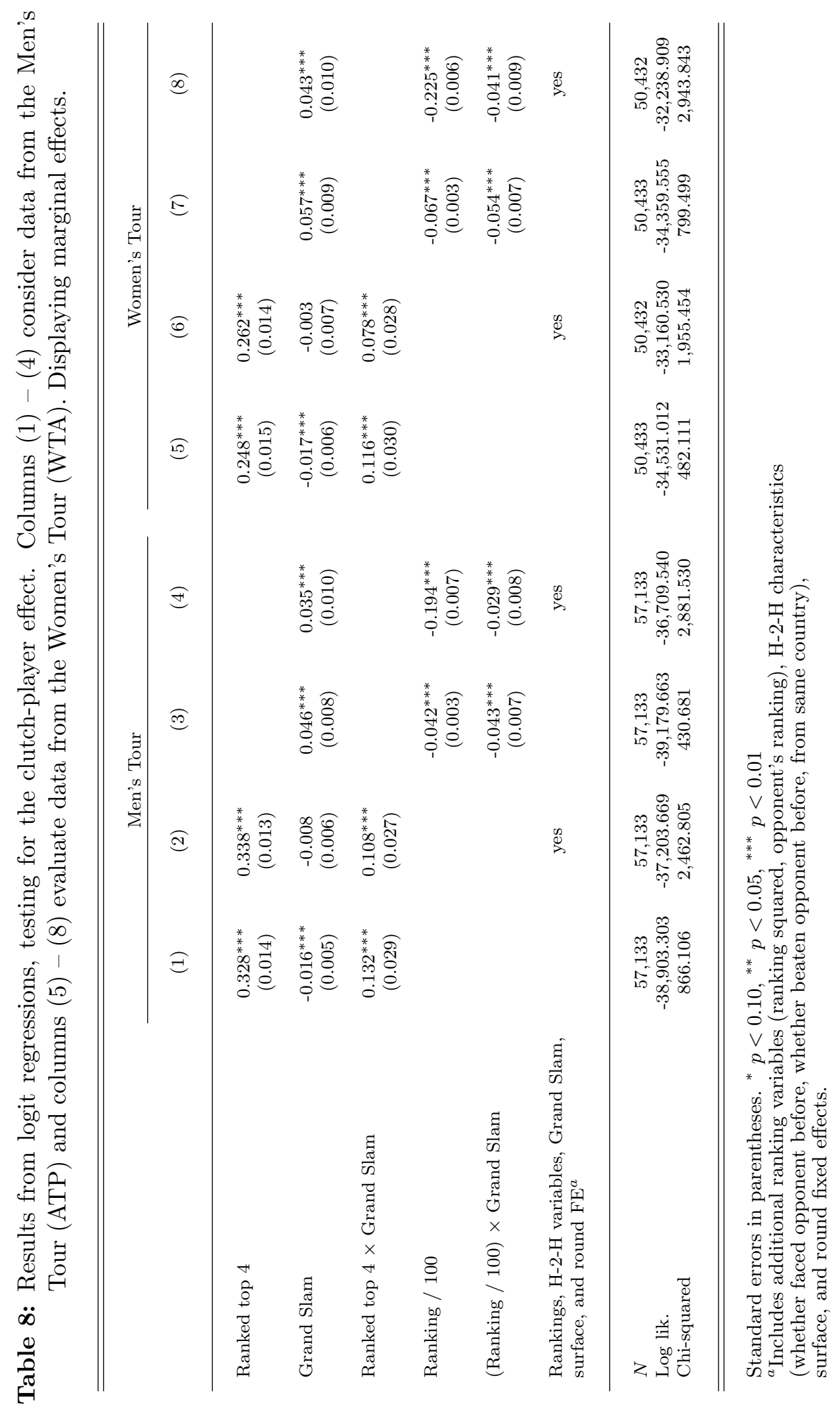




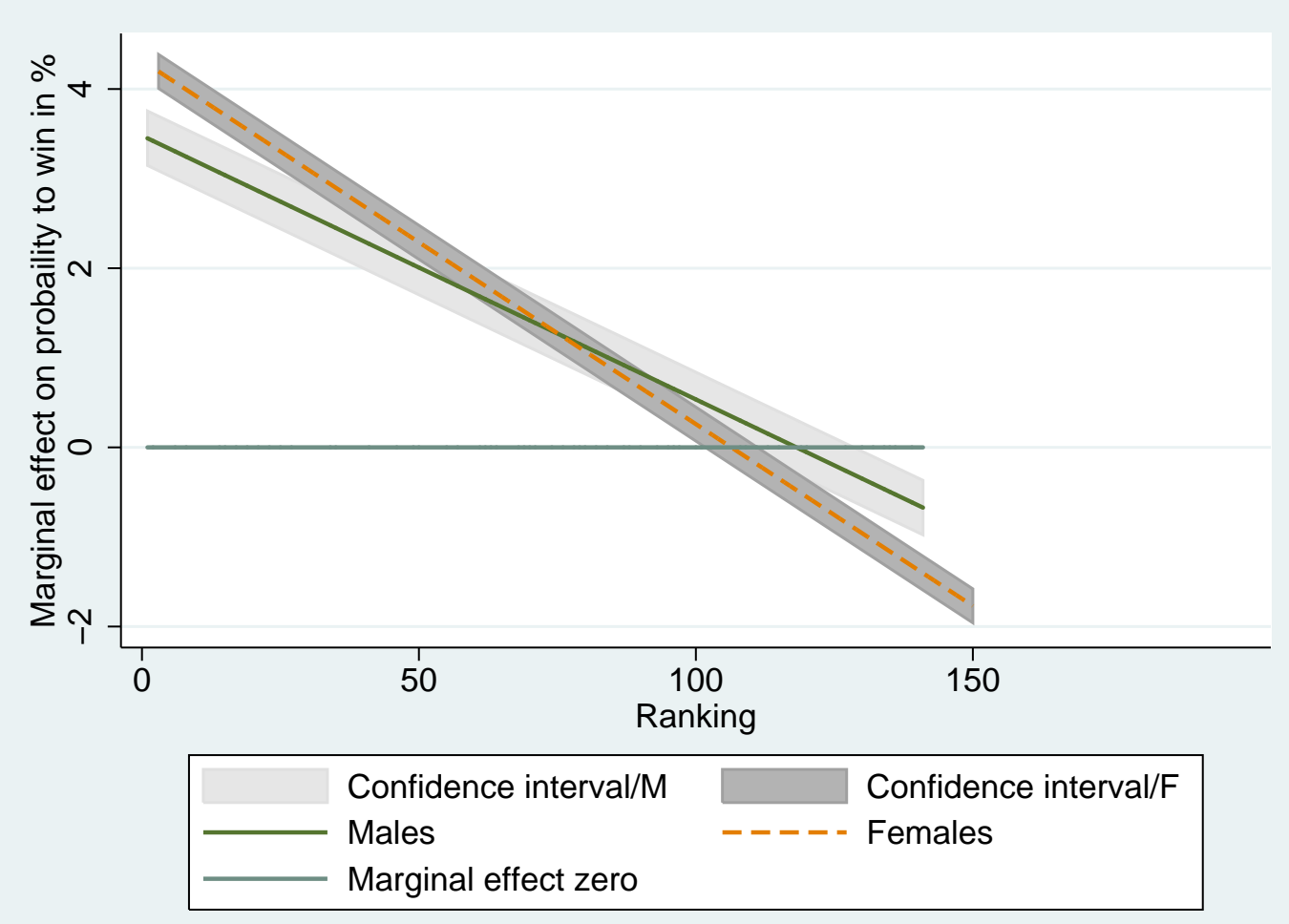

Figure 2: Marginal effects of ranking on winning the match when playing in Grand Slam.

term between a player's ranking and Grand Slam tournaments. Once again, we find firm support for the clutch-player hypothesis, both for men and women. With this broader measurement, and controlling for our additional covariates, an ATP player ranked \# 20 is 2.9 percentage points more likely to win a match at a Grand Slam event than somebody ranked \# 120. Interestingly, the relationship is now stronger for females, with a suggested effect of 4.1 percentage points.

In fact, the regressions results displayed in columns (4) and (8) allow us to graph the marginal effect of ranking on the probability of winning when playing in a Grand Slam event. The results are displayed in Figure 2, where we focus on the players ranked in the top 150. Notice that for females the marginal effect is steeper and a player ranked \#1 is 4.3 percentage points more likely to win in a Grand Slam match than in a match at any other tournament. For males, the marginal increase in the odds of winning for the best ranked player turn out to be 3.5 percentage points. Note that this effect is isolating the fact that a player is competing at a Grand Slam tournament, controlling for rankings and our usual set of covariates.

Further, the lower end of the graph also provides some evidence for the choking hypothesis 
(Ariely et al., 2009), where large payoffs can hamper one's performance. Although the best ranked players seem to excel in Grand Slam events, players ranked beyond 118 (males) or 106 (females) actually seem to under-perform in these lucrative situations. Thus, one difference between top players and other Tour professionals may be the ability to perform their best in clutch situations.

Table 8 provides firm evidence for the clutch-player effect of top players. Higher prize money, more prestige, and big stages indeed seem to bring out the best performance in top tennis players. The following sections consider crucial moments within matches, evaluating whether top players are more likely to win in final, decisive sets and whether they perform exceptionally well in tie-breaks, the closest form of deciding a set in tennis.

\subsection{Clutch Play within Matches?}

Beyond analyzing the most important tournaments, Grand Slams, another way of testing for clutch-player effects can be found within matches. With the exception of male Grand Slam events and the Davis Cup, matches are usually decided in a best-of-three format. In other words, the player who wins two out of three sets advances in the tournament. In this case, a final, third set presents a win-or-go-home scenario and we would expect top players to prevail in these situations if the clutch-player effect does exist. In Grand Slam and Davis Cup events the format is extended to best-of-five sets with the respective scenario occurring in a potential fifth set.

Table 9 displays regressions from using a subsample of those matches that witnessed a final and decisive set. Overall, this produces 16,536 observations for the male sample and 15,801 matches on the women's side. Thus, 29 percent of the men's matches and 31 percent of the women's matches eventually reached a final and decisive set. In this case, the results are less convincing and the interaction terms of top players (ranked top four; general ranking) with Grand Slam events produces a coefficient that is not statistically significant on conventional levels. One exception is provided by the interaction term between ranking and Grand Slams for males in column (3), but once the usual control variables are added in column (4) statistical importance vanishes. The respective coefficients for the WTA sample, on the other hand, never come close to commonly accepted levels of statistical significance. 


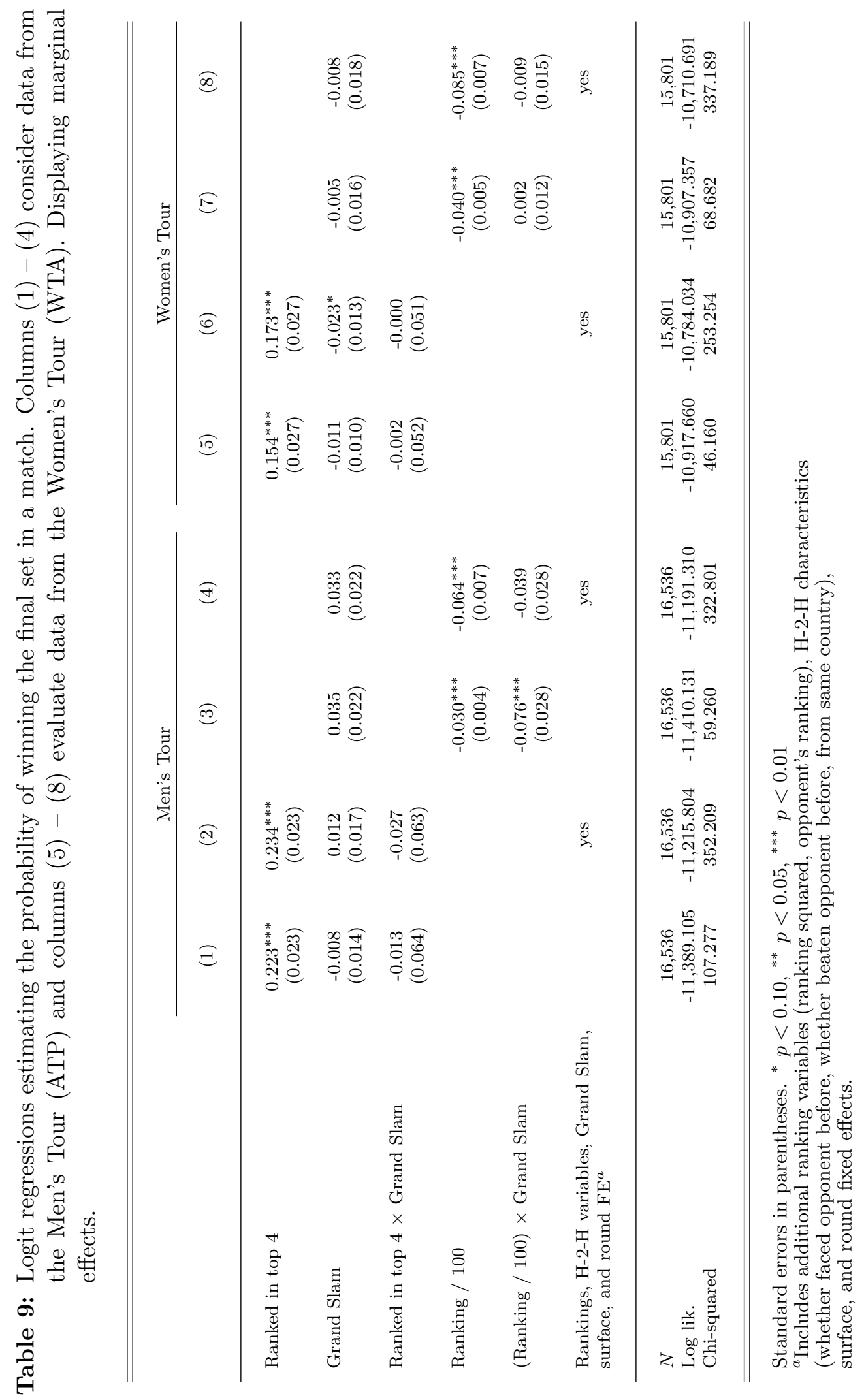


Another clutch situation within a match is provided by the ultimate decision within a set: a tie-break. At a score of 6 to 6 games within a set, the rules prescribe a tie-break, where the first to seven points wins (point differential of two necessary). In fact, the tie-break could be considered as the ultimate form of a clutch-play situation within a tennis match.

Table 10 displays results from logit regressions, estimating the probability of winning a tiebreak. Specifically, we derive a subsample from both the male and the female samples that incorporates those matches that witnessed one tie-break throughout the match. In this case we code the dependent variable as one if the respective player wins the tie-break and zero otherwise. The results produce evidence for clutch-play on the men's side, yet the coefficients from the female subsample are weaker and do not reach conventional levels of statistical importance. ATP players ranked in the top four are over eight percentage points more likely to win a tiebreak at a Grand Slam tournament, relative to other, smaller tournaments. This result remains stable after the inclusion of our set of control variables. Interestingly, the same regression in the female sample produces a similar coefficient (0.082), but lacks statistical relevance. Thus, the difference can be found in the statistical precision of our estimation and we indeed note a much higher standard error in column (6) than in column (2), namely 0.068 versus 0.043 . One explanation could simply be that female superstars are much less likely to reach the tie-break stages and most sets are decided beforehand. In fact, the respective subsample confirms this suspicion as 16,398 matches on the male Tour saw one tie-break, whereas only 9,152 matches on the female Tour did.

Considering a continuous measurement of rankings then confirms this trend. We recover statistical importance on the ten percent level for males, but not for females. In this case the distinction is much clearer, as the final and most complete estimation suggests male players ranked 100 spots better to be 2.2 percentage points more likely to win a tie-break at a Grand Slam tournament, compared to any other event. For WTA Tour matches the implied coefficient would suggest an effect of 1.3 percentage points, although this result is not distinguishably different from zero. Overall, the results from analyzing clutch situations within matches produces less precise conclusions regarding a potential clutch-player effect. 


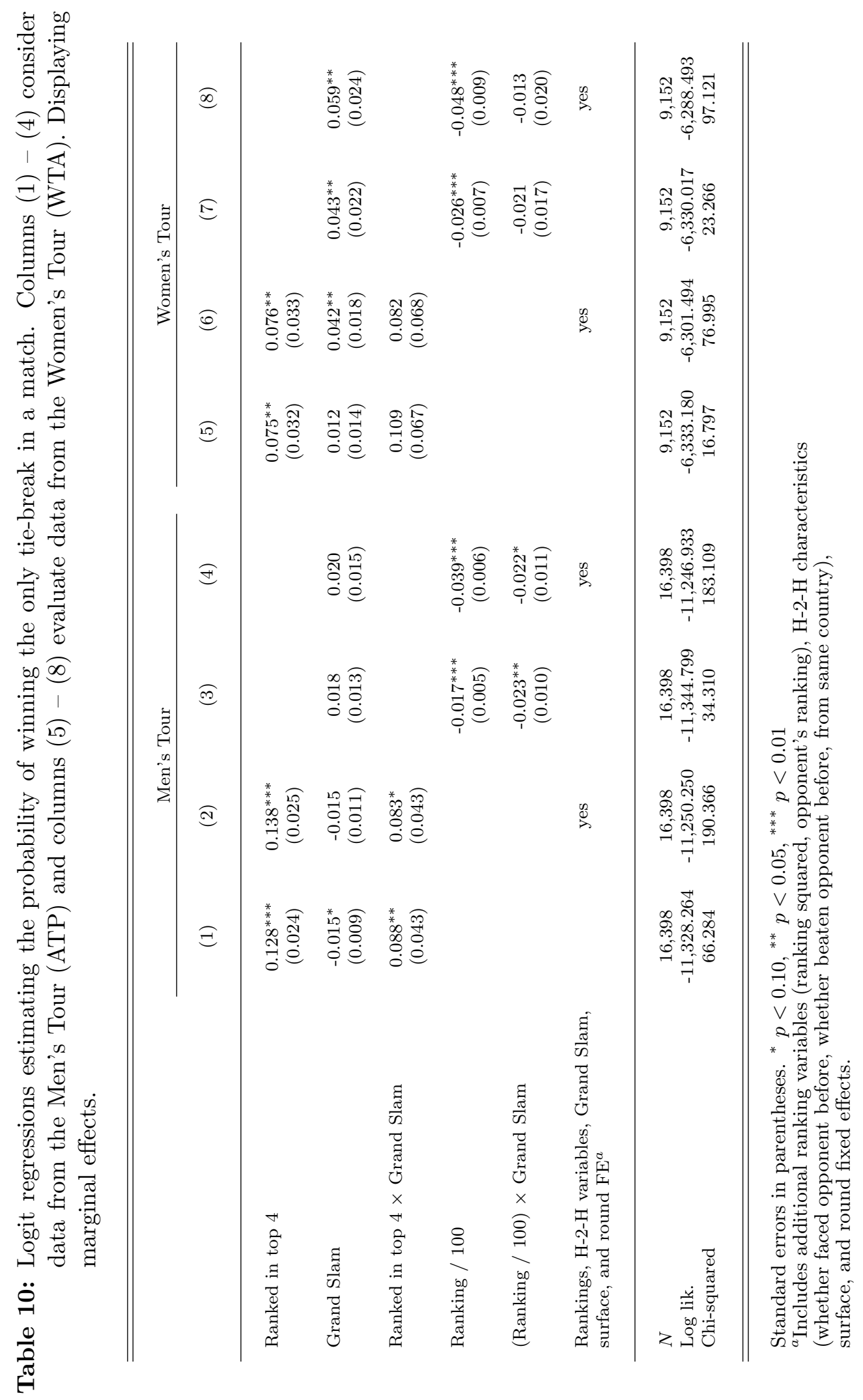




\section{Conclusion}

This paper uses tennis, an individual sport with isolated single-sex labor markets and virtually identical payoff structures, to analyze potential gender differences in competitive behavior. Our study allows for three main conclusions.

First, we find strong evidence for the hot-hand and the cold-hand effect. Recent performance does matter in predicting current outcomes and this result is not only relevant in statistical terms, but also quite sizeable. For example, having won all previous ten matches increases the likelihood of winning the current encounter by over 31 to 33 percentage points. This result is robust to a variety of robustness checks and extensions, confirming and extending Wozniak (2012)'s findings about men's and women's choices to enter professional tennis tournaments and Livingston (2012) who studies the hot-hand effect in professional golf. In addition, losing streaks seem to be punished in the same way as winning streaks are rewarded with respect to the chances of winning the current match.

Second, top players perform strongly at Grand Slam tournaments, arguably the most important events for tennis players. We take this finding as evidence for a clutch-player effect as top players are up to four percentage points more likely to win a given match at a Grand Slam tournament, relative to any other event. This confirms previous findings related to the clutch-player effect in tennis by González-Díaz et al. (2012). We also find some evidence for lower-ranked players performing worse than expected at Grand Slam events, confirming the intuition of large payoffs being able to paralyze an athlete (Ariely et al., 2009). In fact, the ability to perform well in important tournaments may be one distinction between top players and the rest of the field in tennis. In additional estimations, we find that male players are more likely to win tie-breaks at Grand Slam tournaments, although this result is less convincing in statistical terms.

Third and final, both effects show very little differences across gender. Especially analyzing the hot-hand effect produces remarkably similar coefficients for the male and female samples (0.31 versus 0.33$)$. As for the clutch-player effect, top-ranked female players are more likely to perform well in important matches, if anything.

Overall, our results provide additional information for how women and men may or may not behave differently in competitive situations. It is important to note that tennis is by design a labor market where men and women are separated. Thus, it may well be possible that 
gender differences of competitive behavior are more likely to emerge in mixed environments, as suggested by Gneezy et al. (2003). Nevertheless, sports can provide an interesting laboratory to study behavior, given its clear labor market structures. 


\section{References}

Abrevaya, J. (2002). Ladder tournaments and underdogs: Lessons from professional bowling. Journal of Economic Behavior \& Organization, 47(1):87-101.

Alesina, A., Giuliano, P., and Nunn, N. (2013). On the origins of gender roles: Women and the plough. Quarterly Journal of Economics, 128(2):469-530.

Andersen, S., Ertac, S., Gneezy, U., List, J. A., and Maximiano, S. (2013). Gender, competitiveness, and socialization at a young age: Evidence from a matrilineal and a patriarchal society. Review of Economics and Statistics, 95(4):1438-1443.

Apesteguia, J. and Palacios-Huerta, I. (2010). Psychological pressure in competitive environments: Evidence from a randomized natural experiment. American Economic Review, 100(5):2548-2564.

Ariely, D., Gneezy, U., Loewenstein, G., and Mazar, N. (2009). Large stakes and big mistakes. Review of Economic Studies, 76(2):451-469.

Bar-Eli, M., Avugos, S., and Raab, M. (2006). Twenty years of hot hand research: Review and critique. Psychology of Sport and Exercise, 7(6):525-553.

Burda, M., Hamermesh, D. S., and Weil, P. (2013). Total work and gender: Facts and possible explanations. Journal of Population Economics, 26(1):239-261.

Byrnes, J. P., Miller, D. C., and Schafer, W. D. (1999). Gender differences in risk taking: A meta-analysis. Psychological Bulletin, 125(3):367.

Croson, R. and Sundali, J. (2005). The gambler's fallacy and the hot hand: Empirical data from casinos. Journal of Risk and Uncertainty, 30(3):195-209.

Dohmen, T. J. (2008). Do professionals choke under pressure? Journal of Economic Behavior \& Organization, 65(3):636-653.

Duggan, M. and Levitt, S. D. (2002). Winning isn't everything: Corruption in sumo wrestling. American Economic Review, 92(5):1594-1605.

Eckel, C. C. and Füllbrunn, S. (2015). Thar she blows? Gender, competition, and bubbles in experimental asset markets. American Economic Review, 105(2):906-20.

Gilovich, T., Vallone, R., and Tversky, A. (1985). The hot hand in basketball: On the misperception of random sequences. Cognitive Psychology, 17(3):295-314.

Gneezy, U., Niederle, M., Rustichini, A., et al. (2003). Performance in competitive environments: Gender differences. Quarterly Journal of Economics, 118(3):1049-1074.

González-Díaz, J., Gossner, O., and Rogers, B. W. (2012). Performing best when it matters most: Evidence from professional tennis. Journal of Economic Behavior 85 Organization, $84(3): 767-781$. 
Grove, W. A., Hussey, A., and Jetter, M. (2011). The gender pay gap beyond human capital: Heterogeneity in noncognitive skills and in labor market tastes. Journal of Human Resources, $46(4): 827-874$.

Guillaume, M., Len, S., Tafflet, M., Quinquis, L., Montalvan, B., Schaal, K., Nassif, H., Desgorces, F. D., and Toussaint, J.-F. (2011). Success and decline: Top 10 tennis players follow a biphasic course. Medicine and Science in Sports and Exercise, 43(11):2148-2154.

Kahn, L. M. (2000). The sports business as a labor market laboratory. Journal of Economic Perspectives, 14(3):75-94.

Lazear, E. P. (2000). Performance pay and productivity. American Economic Review, 90(5):1346-1361.

Livingston, J. A. (2012). The hot hand and the cold hand in professional golf. Journal of Economic Behavior $\&$ Organization, 81(1):172-184.

Niederle, M. (2014). Gender. NBER Working Paper 20788.

Niederle, M. and Vesterlund, L. (2007). Do women shy away from competition? Do men compete too much? Quarterly Journal of Economics, 122(3):1067-1101.

Niederle, M. and Vesterlund, L. (2010). Explaining the gender gap in math test scores: The role of competition. Journal of Economic Perspectives, 24(2):129-144.

Niederle, M. and Vesterlund, L. (2011). Gender and competition. Annu. Rev. Econ., 3(1):601630.

Rabin, M. and Vayanos, D. (2010). The gambler's and hot-hand fallacies: Theory and applications. Review of Economic Studies, 77(2):730-778.

Topping, A. (2015). Gender pay gap will not close for 70 years at current rate, says UN. The Guardian, March 5, 2015.

Wozniak, D. (2012). Gender differences in a market with relative performance feedback: Professional tennis players. Journal of Economic Behavior $\& 3$ Organization, 83(1):158-171. 